\title{
Numerical Modelling of Lean Duplex Stainless Steel and Assessment of Existing Design Methods
}

\author{
By Najib Saliba* \\ Johnny Issa ${ }^{\dagger}$
}

The longevity and unique mechanical properties of stainless steel are sufficient reasons for adopting it as a main material in the construction industry. However, its high initial cost, which is largely influenced by the level of nickel content (8\% - 10\% in the common austenitic grade), relatively restricts its application in structures. The development of lean duplex stainless steel, a low nickel grade offering twice the strength of the austenitic grade at nearly half the initial cost, and refining the codified design equations, may increase the usage rate of stainless steel in construction. The aim of this paper is to continue the previous research conducted on lean duplex stainless steel by providing more data on its structural performance using numerical modelling and evaluating existing and proposed design equations which were not available earlier. A detailed description of the modelling using the general-purpose finite element analysis package ABAQUS is presented. Forty-eight lean duplex stainless steel welded I-sections loaded in bending and shear were simulated. The obtained numerical results are reported and used in conjunction with existing experimental and numerical data on stainless steel welded I-sections to assess the Eurocode 3: Part 1.4 codified slenderness limits and shear resistance design equations, the continuous strength method (CSM) for bending and newly proposed shear design equations. Analysis of the results reveals that the current codified design provisions are generally conservative and improved predictions can be achieved using the CSM and the proposed slenderness limits and shear resistance equations.

Keywords: Bending, Continuous strength method, Cross-section classification, Finite element, Lean duplex, Numerical modelling, Shear, Stainless steel, Welded I-sections.

\section{Introduction}

Stainless steel is known for its distinctive properties such as its high strength, corrosion resistance, stiffness and ductility, durability, fire resistance, relatively low maintenance fees and recyclability (Gardner, 2005). However, the benefits of adopting stainless steel as a main structural component in the construction industry are relatively overlooked by designers and engineers. This may be largely attributed to: 1) its high initial cost (approximately four times the cost of carbon steel) which is largely influenced by the level of nickel content, $8 \%$ to $10 \%$ in the most commonly used austenitic grade and 2) conservative design codes. In regards to the latter, the drawbacks of the current stainless steel design codes go back to their development phase in which they were greatly based on carbon steel guidelines (to facilitate its implementation by engineers) and limited structural

\footnotetext{
* Assistant Professor, Department of Civil Engineering, University of Balamand, Lebanon.

${ }^{\dagger}$ Assistant Professor, Department of Mechanical Engineering, University of Balamand, Lebanon.
} 
performance data (Gardner, 2005; Estrada et al., 2007b; Ashraf et al., 2008; Gardner and Theofanous, 2008; Afshan and Gardner, 2013). Stainless steel, contrary to carbon steel, is characterized by a rounded (nonlinear) stress-strain curve with no sharply defined yield point and considerable strain hardening. Hence, design equations based on carbon steel (i.e. founded on the idealized elastic, perfectly plastic material behaviour and ignoring strain hardening effects) may lead to exceedingly conservative designs.

With the recent development of a low nickel stainless steel known as lean duplex stainless steel (LDSS) (EN 1.4162) (EN 10088-4, 2009), subset of the duplex family, the potential for the usage of stainless steel as a main structural component increases. Despite its low nickel content (approximately 1.5\%) and hence relatively reduced initial cost, lean duplex retains higher strength than the austenitic grades and maintains the unique characteristics of stainless steel (Saliba, 2012). A typical lean duplex stainless steel stress-strain diagram is presented in Figure 1. Research on the structural performance of LDSS has been carried out in the past few years in order to understand its behaviour and allow its incorporation into structural design codes (Sieurin et al., 2007; Theofanous and Gardner, 2009; Theofanous and Gardner, 2010; Hassanein, 2011; Huang and Young, 2012; Patton and Singh, 2012; Patton and Singh, 2013; Saliba and Gardner, 2013a; Saliba and Gardner 2013b, Huang and Young, 2014; Sachidananda and Singh, 2015; Anbarasu and Ashraf, 2016). These studies investigated both the material characteristics of LDSS and the performance of commonly used cross-sections such as circular hollow sections (CHS), square hollow sections (SHS), rectangular hollow sections (RHS) and welded I-sections. Nevertheless, carrying out more research on the structural behaviour of LDSS and further refining the current codified design equations are vital to persuade engineers to adopt LDSS as a main structural component in construction. This may also encourage the usage of structural stainless steel as an economical choice rather than an expensive option only.

It is therefore the aim of this present study to continue the research on lean duplex stainless steel welded I-sections initiated by Saliba and Gardner (2013a; 2013b) - a summary of their main findings is presented in the relevant subsections of the literature review. This paper provides a detailed description of the numerical programme carried out to gather further data on LDSS welded I-sections. A brief summary of the available laboratory test data on LDSS welded I-sections is presented. Existing codified design methods and proposals for cross-section slenderness limits and shear resistance calculations, and the continuous strength method (CSM) for bending are discussed. The obtained numerical results are reported and used in conjunction with existing test data to assess the applicability of the codified slenderness limits employed in EN 1993-1-4 (2006) and those proposed by Gardner and Theofanous (2008), shear resistance design equations of EN 1993-1-4 (2006), EN 1993-1-5 (2006) and those recently proposed by Saliba et al. (2014) and the continuous strength method (CSM) for bending (Afshan and Gardner, 2013). Finally, design recommendations are made based on the reported data in the literature. 
Figure 1. Typical Lean Duplex Stainless Steel Stress-strain Diagram (Saliba and Gardner, 2013b)

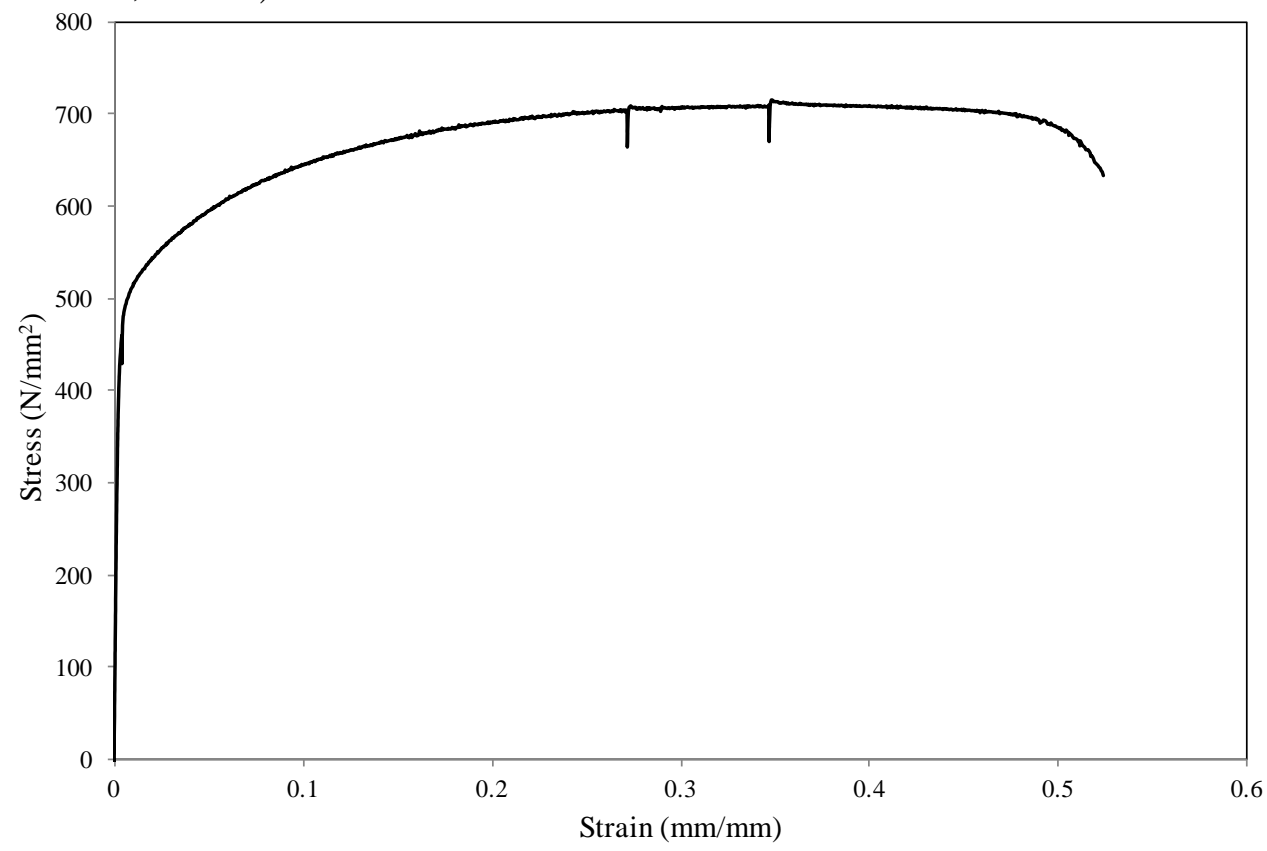

\section{Literature Review}

This section provides a brief overview of the data available on stainless steel welded I-sections, the codified and newly developed proposed design equations for both bending and shear, and the continuous strength method for bending.

\section{Existing Structural Performance Data on Stainless Steel Welded I-sections}

The structural behaviour of stainless steel cross-sections has been the focus of different researchers over the past decades. However, the studies carried out on welded I-sections are rather limited. The available test data on stainless steel welded I-sections were gathered by Saliba (2012) in which 36 sections of the austenitic and duplex grades were reported. These included in-plane bending tests and shear tests. By the time of the collection of these data limited studies on LDSS cross-sections existed but none on welded I-sections.

The first laboratory tests to investigate the behaviour of LDSS welded Isections were carried out by Saliba and Gardner (2013a; 2013b). Their experimental programme included material tests, pure axial compression, inplane bending and shear tests. The main findings of their study were: (1) on a normalized basis, the behaviour of lean duplex stainless steel is analogous to other stainless steel grades of equivalent sections; (2) Eurocode 3: Part 1.4 (2006) provisions may be safe to use but are overly conservative; (3) it is essential to increase the number of existing data, experimentally and numerically, on LDSS welded I-sections; and (4) it is vital to explore and adopt new design methods to allow for more economical and efficient designs. 


\section{Eurocode Design Recommendations and Proposed Equations}

The European pre-standard ENV1993-1-4 (1996) was based on the findings of the joint project managed by the UK Steel Construction Institute (Baddoo, 2008). This standard was later converted to the current, and latest international, full European standard EN 1993-1-4 (2006).

\section{Cross-section Classification}

The similarities between EN 1993-1-4 (2006) and EN 1993-1-1 (2005) are reflected through the adoption of the same classification process with some differences in the slenderness limits and effective width formulae. According to the EN1993-1-4 (2006) rules, based on the width-to-thickness ratios of the constituent elements, cross-sections can be classified as Class 1 (reaches and sustains plastic moment capacity, $\mathrm{M}_{\mathrm{pl}}$ ), 2 (attains $\mathrm{M}_{\mathrm{pl}}$ only), 3 (achieves elastic moment capacity, $\mathrm{M}_{\mathrm{el}}$ ) or 4 (local buckling prevents the attainment of $\mathrm{M}_{\mathrm{el}}$ ). Those limits were investigated by Gardner and Theofanous (2008) and accordingly, new slenderness limits and effective width formulae (for treatment of local buckling) were proposed and validated.

A detailed investigation on the cross-section classification process and a comparison between the current codified limits for carbon steel and stainless steel can be found in Gardner and Theofanous (2008) and Saliba (2012).

\section{Shear Buckling Resistance}

In the development of the design shear buckling resistance for carbon steel plate girders two main methods were considered: the simple post critical method and the tension field method. These two methods had several limitations (Davies and Griffith, 1999; Presta et al., 2008), therefore the rotated stress field method (Höglund, 1998) formed the basis of the shear design rules given in EN 1993-1-5 (2006). In the case of stainless steel, the current codified equations (EN1993-1-4, 2006) are also based on the rotated stress field method, and follow the same basic form as those of carbon steel. However, contrary to EN 1993-1-5 (2006), both rigid and non-rigid end posts are treated similarly in EN 1993-1-4 (2006). The ultimate shear buckling resistance $\mathrm{V}_{\mathrm{b}, \mathrm{Rd}}$ of stainless steel plate girders according to EN 1993-1-4 (2006) is as given by Equation (1), where $V_{b w, R d}$ and $V_{b f, R d}$ are the web and flange contributions, respectively.

$$
\mathrm{V}_{\mathrm{b}, \mathrm{Rd}}=\mathrm{V}_{\mathrm{bw}, \mathrm{Rd}}+\mathrm{V}_{\mathrm{bf}, \mathrm{Rd}} \leq \frac{\eta f_{\mathrm{yw}} \mathrm{h}_{\mathrm{ww}} \mathrm{t}_{\mathrm{w}}}{\sqrt{3} \gamma_{\mathrm{M} 1}}
$$

where $\eta$ is a factor that approximates the influence of strain hardening and is equal to $1.2, \mathrm{f}_{\mathrm{yw}}$ is the yield strength of the web, $\mathrm{h}_{\mathrm{w}}$ is the depth of the web, $\mathrm{t}_{\mathrm{w}}$ is the thickness of the web and $\gamma_{\mathrm{M} 1}$ is the shear partial factor. The web contribution is given by Equation (2): 
$\mathrm{V}_{\mathrm{bw}} \mathrm{Rd}=\frac{\gamma_{\mathrm{w}} \mathrm{f}_{\mathrm{yw}} \mathrm{h}_{\mathrm{w}} \mathrm{t}_{\mathrm{w}}}{\sqrt{3} \gamma_{\mathrm{M} 1}}$

where $\chi_{w}$ is the web shear buckling reduction factor defined by Equation (3) according to EN 1993-1-4 (2006):

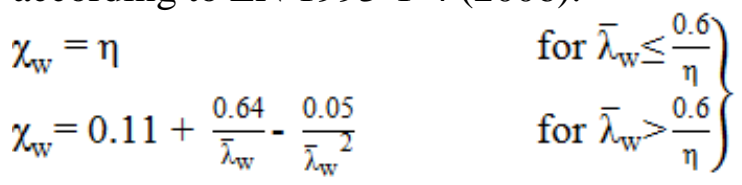

The flange contribution $\mathrm{V}_{\mathrm{bf}, \mathrm{Rd}}$ is given by Equation (4):

$\mathrm{V}_{\mathrm{bf}, \mathrm{Rd}}=\left(\frac{\mathrm{b}_{\mathrm{ft}} \mathrm{t}^{2} \mathrm{f}_{\mathrm{yf}}}{\mathrm{c}_{\mathrm{M} 1}}\right)\left(1-\left(\frac{\mathrm{M}_{\mathrm{Ed}}}{\mathrm{M}_{\mathrm{f}, \mathrm{Rd}}}\right)^{2}\right)$

with the distance c defined by Equation (5):

$\mathrm{c}=\left(0.17+\frac{3.5 \mathrm{~b}_{\mathrm{ft}} \mathrm{tf}^{2} \mathrm{f}_{\mathrm{yf}}}{\mathrm{t}_{\mathrm{w}} \mathrm{h}_{\mathrm{w}}{ }^{2} \mathrm{f}_{\mathrm{yw}}}\right) \mathrm{a}$ with $\stackrel{\mathrm{c}}{\mathrm{a}} \leq 0.65$

where $b_{f}$ is the flange width, $t_{f}$ is the flange thickness, $f_{y f}$ is the yield strength of the flange, $\mathrm{M}_{\mathrm{Ed}}$ is the design bending moment, $\mathrm{M}_{\mathrm{f}, \mathrm{Rd}}$ is the design plastic moment of resistance of a cross-section consisting of the flanges only and a is the shear panel length.

Further research was carried out to assess the codified stainless steel shear resistance equations by Estrada et al. (2007a, 2007b) and Saliba and Gardner (2013b). Their studies highlighted the conservatism of the code and the importance of differentiating between rigid and non-rigid end posts. Therefore, Saliba et al. (2014) proposed revised shear buckling reduction factors $\left(\chi_{\mathrm{w}}\right)$, presented in Table 1 . These account for end post rigidity and offer better shear resistance predictions, while maintaining the same equations of EN 1993-1-4 (2006) (Equations (1) - (2) and (4) - (5)) for the calculation of the ultimate shear capacity of stainless steel plate girders. Note that the recommended value of $\eta$ is 1.2 .

Table 1. Saliba et al. (2014) Proposed Shear Buckling Reduction Factors $\chi_{w}$

\begin{tabular}{|l|c|c|}
\hline & $\chi_{w}$ for rigid end post & $\chi_{w}$ for non-rigid end post \\
\hline $\bar{\lambda}_{\mathrm{W}} \leq 0.65 / \eta$ & $\eta$ & $\eta$ \\
\hline $0.65 / \eta \bar{\lambda}_{\mathrm{wV}} 0.65$ & $0.65 / \bar{\lambda}_{\mathrm{W}}$ & $0.65 / \bar{\lambda}_{\mathrm{W}}$ \\
\hline $\bar{\lambda}_{\mathrm{W}} \geq 0.65$ & $1.56 /\left(0.91+\bar{\lambda}_{\mathrm{w}}\right)$ & $1.19 /\left(0.54+\bar{\lambda}_{\mathrm{w}}\right)$ \\
\hline
\end{tabular}

$\underline{\text { Continuous Strength Method }}$ 
The current codified approach for stainless steel assumes elastic, perfectly plastic material behaviour with a maximum attainable stress of $0.2 \%$ proof stress. This generally leads to conservative results when considering stainless steel crosssections. The continuous strength method (CSM) was recently developed to overcome this conservatism. It is a novel design approach, represents a deviation from the traditional cross-section classification, which allows for a better exploitation of the material strain hardening characteristics, based on a continuous relationship between cross-sectional slenderness and deformation capacity (Gardner, 2008; Gardner et al. 2011; Afshan and Gardner, 2013). The latest improvements to the method are presented in Afshan and Gardner (2013) and their key design expressions, given by Equations (6) - (11), were adopted in this paper and are briefly described herein. It is worth noting that the development of the CSM to the determination of shear resistance is underway and initial findings are reported in Saliba and Gardner (2015).

The cross-section slenderness is calculated through Equation (6):

$\bar{\lambda}_{\mathrm{p}}=\sqrt{\frac{\sigma_{0.2}}{\sigma_{\mathrm{cr}}}}$

where $\sigma_{0.2}$ is the material $0.2 \%$ proof stress and $\sigma_{\mathrm{cr}}$ is the elastic buckling stress of the full cross-section, or conservatively, the most slender constituent plate element.

The deformation capacity $\varepsilon_{\mathrm{csm}} / \varepsilon_{\mathrm{y}}$ is given by Equation (7):

$$
\frac{\varepsilon_{\mathrm{csm}}}{\varepsilon_{\mathrm{y}}}=\frac{0.25}{\bar{\lambda}_{\mathrm{p}}^{3.6}} \quad \text { but } \frac{\varepsilon_{\mathrm{csm}}}{\varepsilon_{\mathrm{y}}} \leq \min \left(15, \frac{0.10 \varepsilon_{\mathrm{u}}}{\varepsilon_{\mathrm{y}}}\right) \text { for } \bar{\lambda}_{\mathrm{p}} \leq 0.68
$$

where $\varepsilon_{\mathrm{y}}=\sigma_{0.2} / \mathrm{E}$ is the yield strain of the material, $\mathrm{E}$ is the Young's modulus, $\varepsilon_{\mathrm{csm}}$ is the CSM limiting strain of the section, and $\varepsilon_{\mathrm{u}}$ is the strain at the ultimate tensile stress.

The CSM limiting stress $\sigma_{\mathrm{csm}}$ is determined according to Equation (8):

$$
\sigma_{\mathrm{csm}}=\sigma_{0.2}+\mathrm{E}_{\mathrm{sh}} \varepsilon_{\mathrm{y}}\left(\frac{\varepsilon_{\mathrm{csm}}}{\varepsilon_{\mathrm{y}}}-1\right)
$$

where $E_{\mathrm{sh}}$ is the strain-hardening slope, calculated for stainless steel from Equation (9):

$$
\mathrm{E}_{\mathrm{sh}}=\frac{\sigma_{\mathrm{u}}-\sigma_{0.2}}{0.16 \varepsilon_{\mathrm{u}}-\varepsilon_{\mathrm{y}}}
$$

where $\sigma_{\mathrm{u}}$ is the ultimate tensile stress of the material and $\varepsilon_{\mathrm{u}}=1-\sigma_{0.2} / \sigma_{\mathrm{u}}$ is used to approximate the strain corresponding to $\sigma_{\mathrm{u}}$. 
Finally, the cross-section compression resistance for I-sections $\mathrm{N}_{\mathrm{csm}, \mathrm{Rd}}$ and major axis bending resistance $\mathrm{M}_{\mathrm{y}, \mathrm{csm}, \mathrm{Rd}}$ are calculated according to Equations (10) and (11):

$$
\begin{aligned}
& \mathrm{N}_{\mathrm{c}, \mathrm{Rd}}=\mathrm{N}_{\mathrm{csm}, \mathrm{Rd}}=\frac{\mathrm{A \sigma}_{\mathrm{csm}}}{\gamma_{\mathrm{MM} 0}} \\
& \mathrm{M}_{\mathrm{y}, \mathrm{c}, \mathrm{Rd}}=\mathrm{M}_{\mathrm{y}, \mathrm{csm}, \mathrm{Rd}}=\frac{\mathrm{W}_{\mathrm{ply}, \mathrm{f}} \mathrm{f}_{\mathrm{Y}}}{\gamma_{\mathrm{M} 0}}\left[1+\frac{\mathrm{E}_{\mathrm{sh}}}{\mathrm{E}} \frac{\mathrm{W}_{\mathrm{el}, \mathrm{y}}}{\mathrm{W}_{\mathrm{pl}, \mathrm{y}}}\left(\frac{\varepsilon_{\mathrm{csm}}}{\varepsilon_{\mathrm{y}}}-1\right)\left(1-\frac{\mathrm{W}_{\mathrm{el}, \mathrm{y}}}{\mathrm{W}_{\mathrm{pl}, \mathrm{y}}}\right) /\left(\frac{\varepsilon_{\mathrm{csm}}}{\varepsilon_{\mathrm{y}}}\right)^{2}\right]
\end{aligned}
$$

where $\mathrm{A}$ is the gross-cross-sectional area, $\mathrm{W}_{\mathrm{el}, \mathrm{y}}$ and $\mathrm{W}_{\mathrm{pl,y}}$ are the major axis elastic and plastic section moduli respectively, and $\gamma_{\mathrm{M} 0}$ is the material partial safety factor as recommended in EN 1993-1-4 (2006).

\section{Finite Element Modelling}

\section{Introduction}

Lean duplex stainless steel is a relatively new grade that requires further investigation to assess its structural behaviour and applicability in the construction industry. As discussed earlier, limited studies exist on welded I-sections, therefore the aim of this paper is to increase the data available by using finite element analysis (FEA) to simulate 48 cross-sections loaded in bending (3-point and 4point) and shear. The numerical study was conducted using the finite element software ABAQUS (Hibbitt et al., 2012). A summary of the dimensions of the modelled cross-sections is presented in Table 2. The webs are stiffened transversely and for cross-sections loaded in shear both rigid and non-rigid end posts are considered. Note that the same dimensions were used for the 3-point and 4-point bending tests; the same applies for rigid and non-rigid end post configurations. The simulations reported in this paper required no validations as they are a continuation of the confirmed FE study by Saliba and Gardner (2013a; 2013b).

Mesh

The finite element type S4R was employed to discretize the models. The $\mathrm{S} 4 \mathrm{R}$ is a four-noded doubly curved general purpose shell element with reduced integration and finite membrane strains, it has six degrees of freedom per node and is suitable to the modelling of various shell thicknesses and cross-section slendernesses (Lecce and Rasmussen, 2006). No mesh density analysis was carried out in this study as the same mesh size of Saliba and Gardner (2013a; 2013b) was employed. 
Table 2. Dimensions of the Finite Element Cross-sections Tested under Bending and Shear

\begin{tabular}{|c|c|c|c|c|c|c|c|}
\hline Test type & Cross-section & $\begin{array}{l}\text { Length } \\
\text { L (mm) }\end{array}$ & $\begin{array}{c}\text { Web height } \\
\mathbf{h}_{w}(\mathbf{m m})\end{array}$ & $\begin{array}{c}\text { Flange width } \\
b_{\mathrm{f}}(\mathrm{mm})\end{array}$ & $\begin{array}{c}\text { Flange thickness } \\
\mathbf{t}_{\mathrm{f}}(\mathbf{m m})\end{array}$ & $\begin{array}{c}\text { Web thickness } \\
\mathbf{t}_{\mathrm{w}}(\mathrm{mm})\end{array}$ & $\begin{array}{c}\text { Aspect ratio } \\
\mathbf{a} / \mathbf{h}_{\mathrm{w}}\end{array}$ \\
\hline \multirow{12}{*}{ Bending } & I- $180 \times 120 \times 6 \times 4$ & 2800 & 180 & 120 & 6 & 4 & - \\
\hline & I- $180 \times 120 \times 8 \times 6$ & 2800 & 180 & 120 & 8 & 6 & - \\
\hline & $\mathrm{I}-180 \times 120 \times 10 \times 6$ & 2800 & 180 & 120 & 10 & 6 & - \\
\hline & $\mathrm{I}-180 \times 120 \times 15 \times 4$ & 2800 & 180 & 120 & 15 & 4 & - \\
\hline & I- $190 \times 125 \times 6 \times 4$ & 3400 & 190 & 125 & 6 & 4 & - \\
\hline & $\mathrm{I}-190 \times 125 \times 8 \times 6$ & 3400 & 190 & 125 & 8 & 6 & - \\
\hline & $\mathrm{I}-190 \times 125 \times 10 \times 6$ & 3400 & 190 & 125 & 10 & 6 & - \\
\hline & I- $190 \times 125 \times 15 \times 4$ & 3400 & 190 & 125 & 15 & 4 & - \\
\hline & $\mathrm{I}-200 \times 130 \times 6 \times 4$ & 4000 & 200 & 130 & 6 & 4 & - \\
\hline & I- $200 \times 130 \times 8 \times 6$ & 4000 & 200 & 130 & 8 & 6 & - \\
\hline & $\mathrm{I}-200 \times 130 \times 10 \times 6$ & 4000 & 200 & 130 & 10 & 6 & \\
\hline & $\mathrm{I}-200 \times 130 \times 15 \times 4$ & 4000 & 200 & 130 & 15 & 4 & - \\
\hline \multirow{12}{*}{ Shear } & I- $700 \times 250 \times 12 \times 4-1$ & 1500 & 700 & 250 & 12 & 4 & 1 \\
\hline & $\mathrm{I}-700 \times 250 \times 12 \times 6-1$ & 1500 & 700 & 250 & 12 & 6 & 1 \\
\hline & I- $700 \times 250 \times 12 \times 8-1$ & 1500 & 700 & 250 & 12 & 8 & 1 \\
\hline & $\mathrm{I}-700 \times 250 \times 15 \times 4-1$ & 1500 & 700 & 250 & 15 & 4 & 1 \\
\hline & I- $700 \times 250 \times 15 \times 6-1$ & 1500 & 700 & 250 & 15 & 6 & 1 \\
\hline & I- $700 \times 250 \times 15 \times 8-1$ & 1500 & 700 & 250 & 15 & 8 & 1 \\
\hline & $\mathrm{I}-700 \times 250 \times 12 \times 4-2$ & 3000 & 700 & 250 & 12 & 4 & 2 \\
\hline & I-700×250×12×6-2 & 3000 & 700 & 250 & 12 & 6 & 2 \\
\hline & I- $700 \times 250 \times 12 \times 8-2$ & 3000 & 700 & 250 & 12 & 8 & 2 \\
\hline & I- $700 \times 250 \times 15 \times 4-2$ & 3000 & 700 & 250 & 15 & 4 & 2 \\
\hline & $\mathrm{I}-700 \times 250 \times 15 \times 6-2$ & 3000 & 700 & 250 & 15 & 6 & 2 \\
\hline & I- $700 \times 250 \times 15 \times 8-2$ & 3000 & 700 & 250 & 15 & 8 & 2 \\
\hline
\end{tabular}




\section{Material, Boundary Condition and Load Application}

The material properties adopted in the FE analysis were based on the measured material properties reported by Saliba and Gardner (2013a; 2013b). The stress-strain curves were approximated with the two-stage Ramberg-Osgood model (Ramberg and Osgood, 1943) as modified by Gardner and Ashraf (2006) incorporated into ABAQUS in terms of true stress, $\sigma_{\text {true }}$, and $\log$ plastic strain, $\varepsilon_{m}^{\mathrm{pl}}$. For all the modelled cross-sections, vertical and lateral displacements were restrained at the location of the supports (i.e. at the ends of the beams) whereas longitudinal displacements and rotations about the horizontal axes were restrained at the center of the beams. A concentrated load was applied at the mid-span of the FE models through a bearing plate to avoid any localized failures in the flange.

\section{Method of Analysis}

A linear eigenvalue buckling analysis was first carried out to determine the lowest relevant elastic buckling mode shape. This shape, with chosen amplitude, is used in the following nonlinear analysis as an initial geometric imperfection. Incorporating geometric imperfections in an FE study is essential as the structural behaviour of cross-sections is highly influenced by the presence of these imperfections which arise mainly during production and fabrication phases. The amplitude selected for this study is $t / 1000$, where $t$ is the thickness of the flanges for the bending tests and is the thickness of the web for the shear tests. This amplitude was shown to give accurate results in Saliba and Gardner (2013a) study. Only local imperfections were considered in the FE models as global buckling was prevented. Figure 2 presents an example of the imperfection shapes used for the bending and shear models. The nonlinear analysis was carried out using the Static Riks method, an algorithm that enables effective solutions to be found to unstable problems and adequately traces nonlinear unloading paths (Hibbitt et al., 2012). Finally, residual stresses were ignored as their effect on the behaviour of the cross-sections is negligible (Saliba and Gardner, 2013a).

Figure 2. Typical Imperfection Modes used for FE Bending and Shear Tests

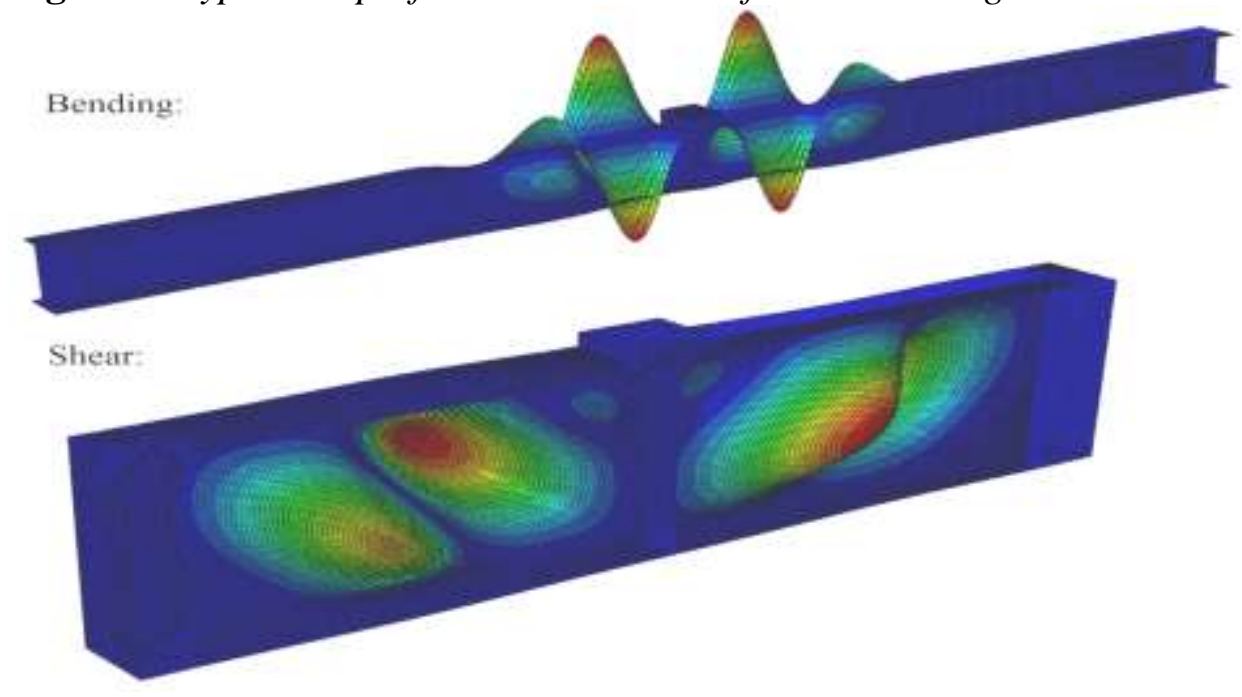


Vol. 5, No. $1 \quad$ Saliba et al.: Numerical Modelling of Lean Duplex Stainless Steel...

\section{Results and Discussion}

\section{Introduction}

The results obtained from the FE analysis are divided into two sections: (1) bending and (2) shear. Typical FE failure modes from the 3-point and 4-point bending test and shear tests are presented in Figure 3. Experimental and numerical data collected from Saliba and Gardner (2013a; 2013b) on LDSS welded Isections are also included in this section. For bending, the codified cross-section classification limits, the proposed limits (Gardner and Theofanous, 2008) and the CSM are assessed. Whereas, for shear the resistance design model of EN 1993-1-4 (2006) and EN 1993-1-5 (2006) are evaluated and comparisons with those proposed by Saliba et al. (2014) are presented.

Figure 3. Typical FE Failure Modes in Bending (3-point and 4-point) and in Shear (Rigid and Non-rigid End Posts) Tests

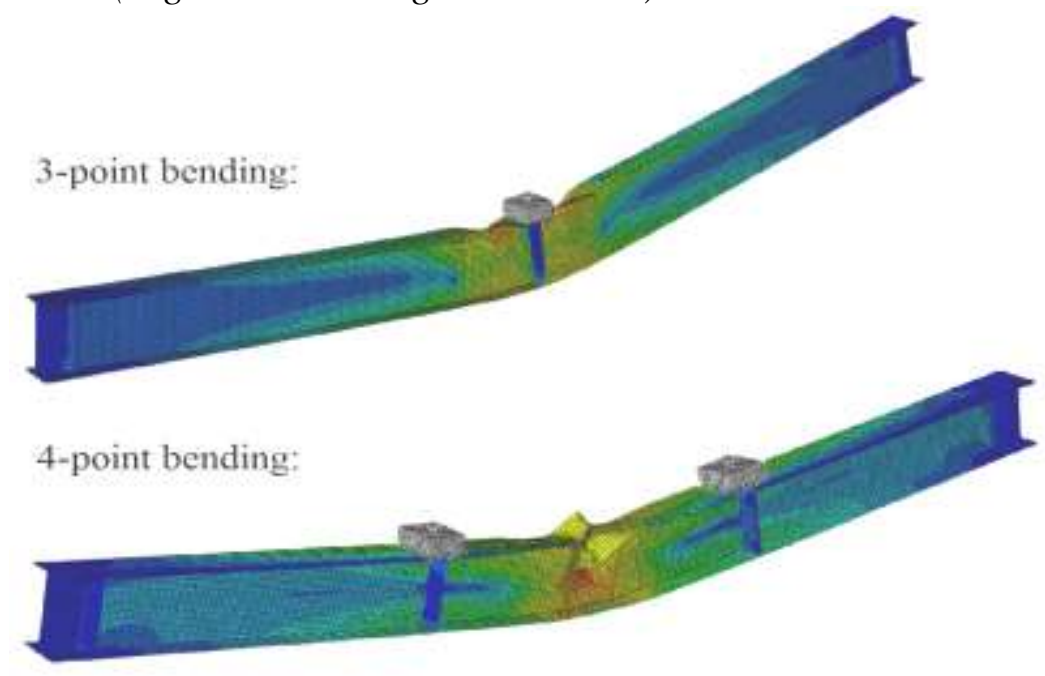

Shear (rigid end post):
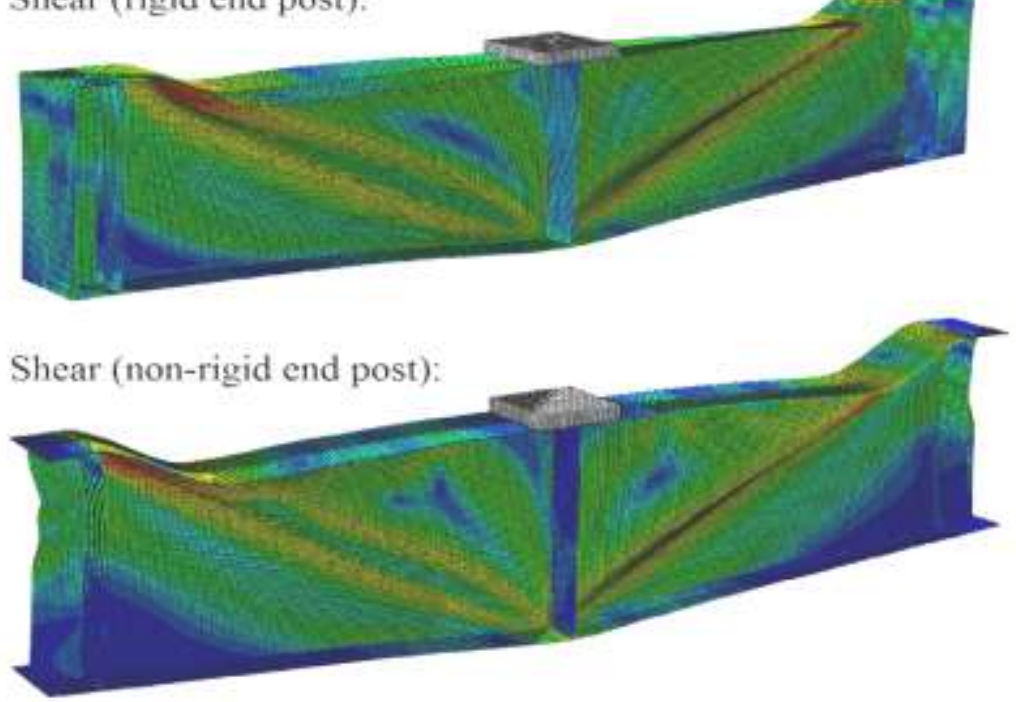


\section{Bending}

\section{$\underline{\text { Cross-section Classification Limits }}$}

As discussed briefly in the literature review, the main issue that arises when considering the codified cross-section classification limits is the fact that these limits were developed by assuming the structural response of stainless steel to be similar to that of carbon steel. A detailed review of the development of these provisions and their limitations can be found in Gardner and Theofanous (2008).

A total of 24 LDSS welded I-sections were modelled using ABAQUS and divided equally between 3-point and 4-point bending tests. It is worth noting that, in general, the resistance obtained from the 3-point bending tests is higher than those of the 4-point configuration - mainly due to the moment gradient of the 3-point bending tests. The most slender element in the majority of the cross-sections was the out-stand flange element with only 6 cross-sections having the web as the most critical element. In Figures 4-7, Classes 3, 2 and 1 slenderness limits are investigated: $\mathrm{M}_{\mathrm{u}} / \mathrm{M}_{\mathrm{el}}, \mathrm{M}_{\mathrm{u}} / \mathrm{M}_{\mathrm{pl}}$, are plotted against $\mathrm{c}_{\mathrm{f}} / \mathrm{t}_{\mathrm{f}} \varepsilon$ (when the flange is critical) and $c_{w} / t_{w} \varepsilon$ (when the web is critical), where $M_{u}$ is the ultimate moment capacity, $c_{f}$ and $c_{w}$ are the width of the outstand flange and web respectively, and $t_{f}$ and $t_{w}$ are the thicknesses of the flange and web respectively. These figures also include results collected from previous studies on LDSS welded I-sections which display a good similarity in the structural response with the FE models reported herein. Table 3 presents a summary of the classification of each of the modelled cross-sections according to both EN 1993-1-4 (2006) and the proposed limits (Gardner and Theofanous, 2008). In general, the proposed limits decreased the number of cross-sections classified as Class 4 according to EN 1993-1-4 (2006) from 3 to 1 and allowed more crosssections to be classified as Classes 1 and 2 rather than Class 3. For example,

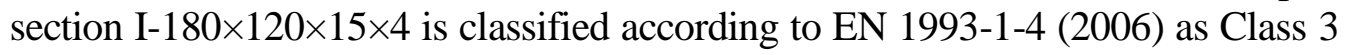
(i.e. it achieves its elastic moment capacity) where according to the proposed limits of Gardner and Theofanous (2008) it can be classified as Class 1 section (i.e. reaches and sustains its plastic moment capacity, $\mathrm{M}_{\mathrm{pl}}$ ). Hence, increased resistances and more efficient designs can be obtained by adopting the Gardner and Theofanous (2008) limits. This can also be observed in Figures 4-7 in which EN 1993-1-4 (2006) and the proposed limits of Gardner and Theofanous (2008) for both welded out-stand flanges in compression and internal webs in bending are presented. The proposed limits of Gardner and Theofanous (2008) of $14 \varepsilon$ and $90 \varepsilon$ for welded outstand flanges in compression and internal webs in bending, respectively, allow for more cross-sections to be considered as Class

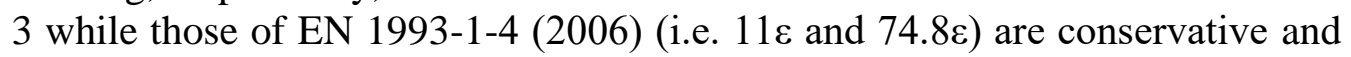
safe to apply. The same can be observed for the Class 2 and Class 1 crosssections in which the codified limits are conservative and further improvements can be obtained if the proposed limits of Gardner and Theofanous (2008) are adopted. 
Table 3. Cross-section Classification according to EN 1993-1-4 (2006) and Proposed Limits (Gardner and Theofanous, 2008)

\begin{tabular}{|c|c|c|c|c|c|}
\hline \multirow{2}{*}{ Cross-section } & \multirow{2}{*}{$\mathbf{c}_{\mathrm{f}} / \mathbf{t}_{\mathrm{f}} \boldsymbol{z}$} & \multirow{2}{*}{$\mathrm{c}_{\mathrm{w}} / \mathbf{t}_{\mathrm{w}} \varepsilon$} & \multirow{2}{*}{ Critical Element } & EN 1993-1-4 (2006) & Proposed Limits (Gardner and Theofanous, 2008) \\
\hline & & & & Class & Class \\
\hline $\mathrm{I}-180 \times 120 \times 6 \times 4$ & 13.32 & 63.02 & Flange & 4 & 3 \\
\hline $\mathrm{I}-180 \times 120 \times 8 \times 6$ & 9.67 & 41.46 & Flange & 3 & 2 \\
\hline $\mathrm{I}-180 \times 120 \times 10 \times 6$ & 7.33 & 39.57 & Flange & 1 & 1 \\
\hline $\mathrm{I}-180 \times 120 \times 15 \times 4$ & 5.25 & 62.11 & Web & 3 & 1 \\
\hline $\mathrm{I}-190 \times 125 \times 6 \times 4$ & 13.96 & 66.86 & Flange & 4 & 3 \\
\hline $\mathrm{I}-190 \times 125 \times 8 \times 6$ & 10.14 & 43.98 & Flange & 3 & 3 \\
\hline $\mathrm{I}-190 \times 125 \times 10 \times 6$ & 7.69 & 41.98 & Flange & 1 & 1 \\
\hline $\mathrm{I}-190 \times 125 \times 15 \times 4$ & 5.50 & 65.90 & Web & 3 & 1 \\
\hline $\mathrm{I}-200 \times 130 \times 6 \times 4$ & 14.60 & 70.71 & Flange & 4 & 4 \\
\hline $\mathrm{I}-200 \times 130 \times 8 \times 6$ & 10.62 & 46.51 & Flange & 3 & 3 \\
\hline $\mathrm{I}-200 \times 130 \times 10 \times 6$ & 8.05 & 44.39 & Flange & 1 & 1 \\
\hline $\mathrm{I}-200 \times 130 \times 15 \times 4$ & 5.76 & 69.69 & Web & 3 & 1 \\
\hline
\end{tabular}


Figure 4. Class 3 Slenderness Limits for Welded Out-stand Flanges in Compression-Assessment and Comparison with Existing Data

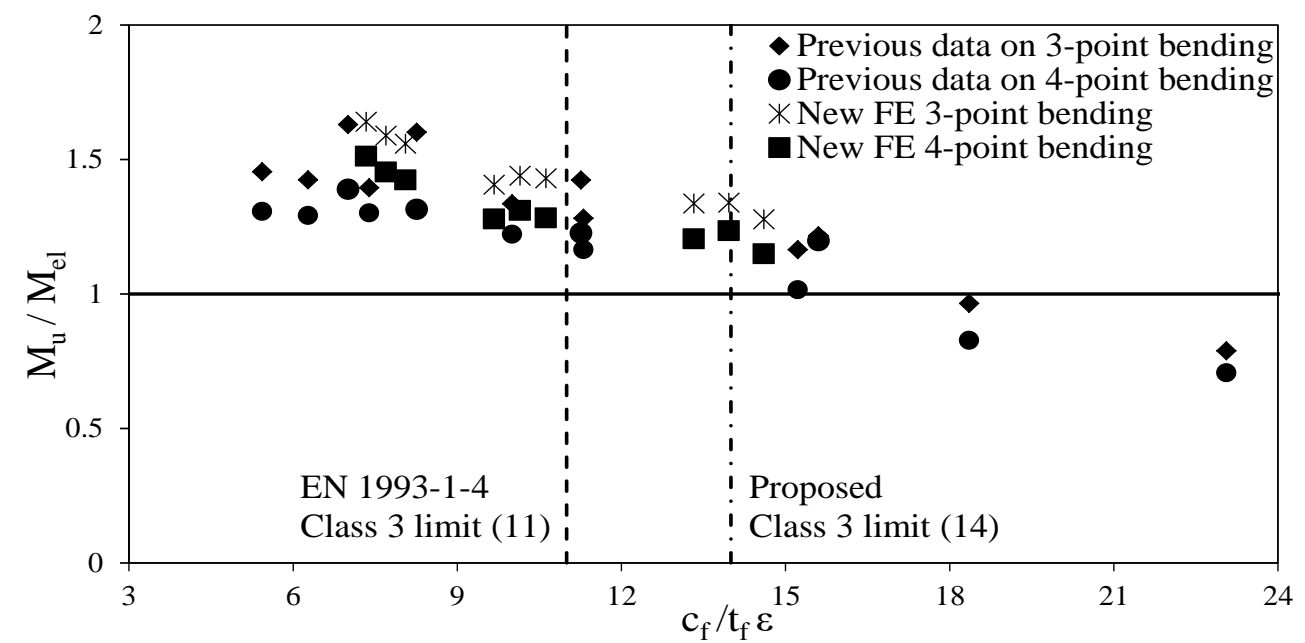

Figure 5. Class 1 and 2 Slenderness Limits for Welded Out-stand Flanges in Compression-Assessment and Comparison with Existing Data

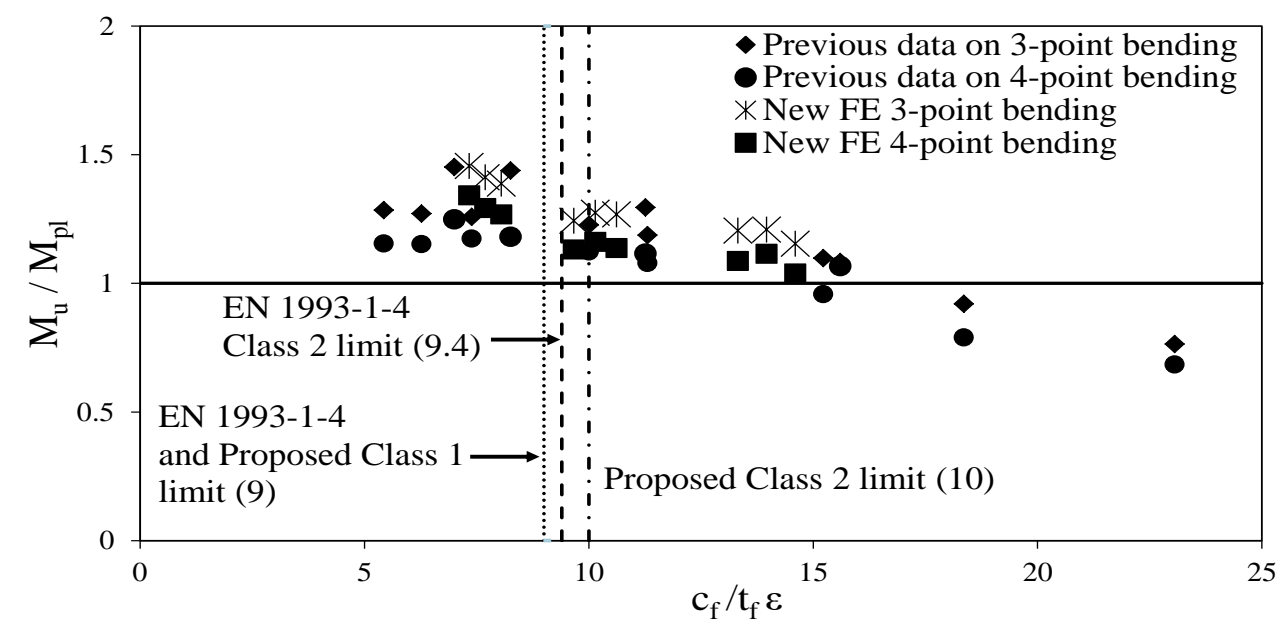

Figure 6. Class 3 Slenderness Limits for Internal Web Elements in BendingAssessment and Comparison with Existing Data

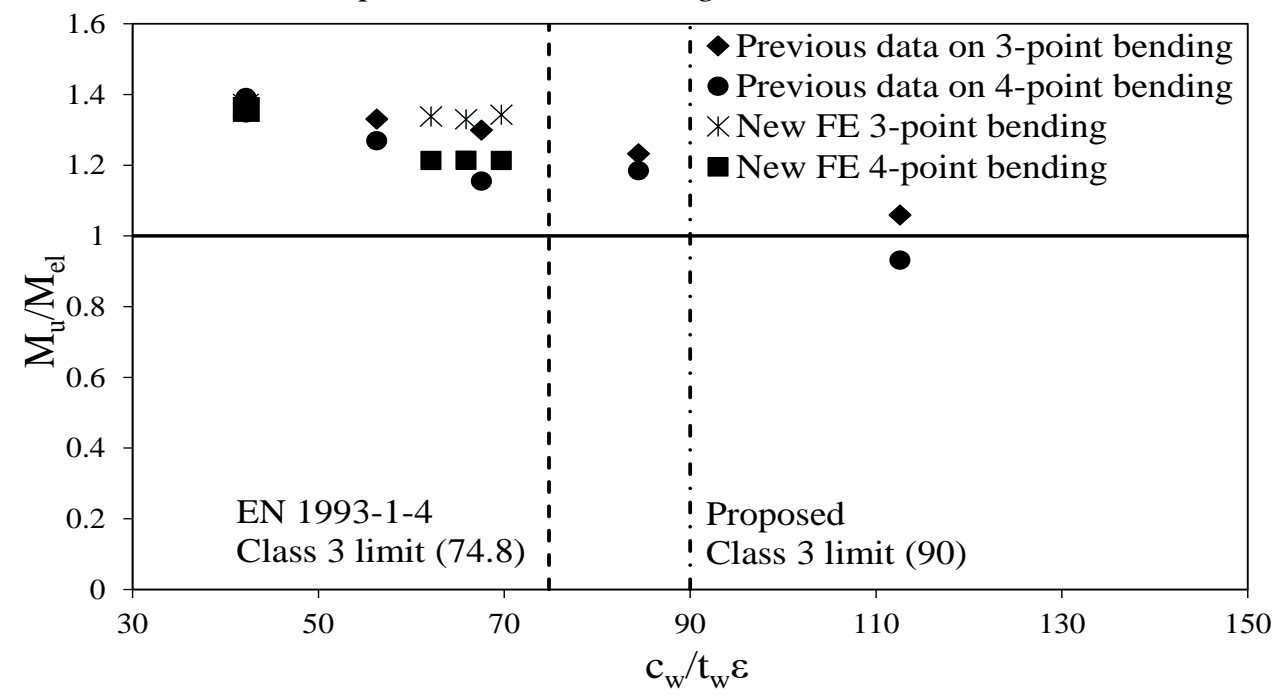


Figure 7. Class 1 and 2 Slenderness Limits for Internal Web Elements in BendingAssessment and Comparison with Existing Data

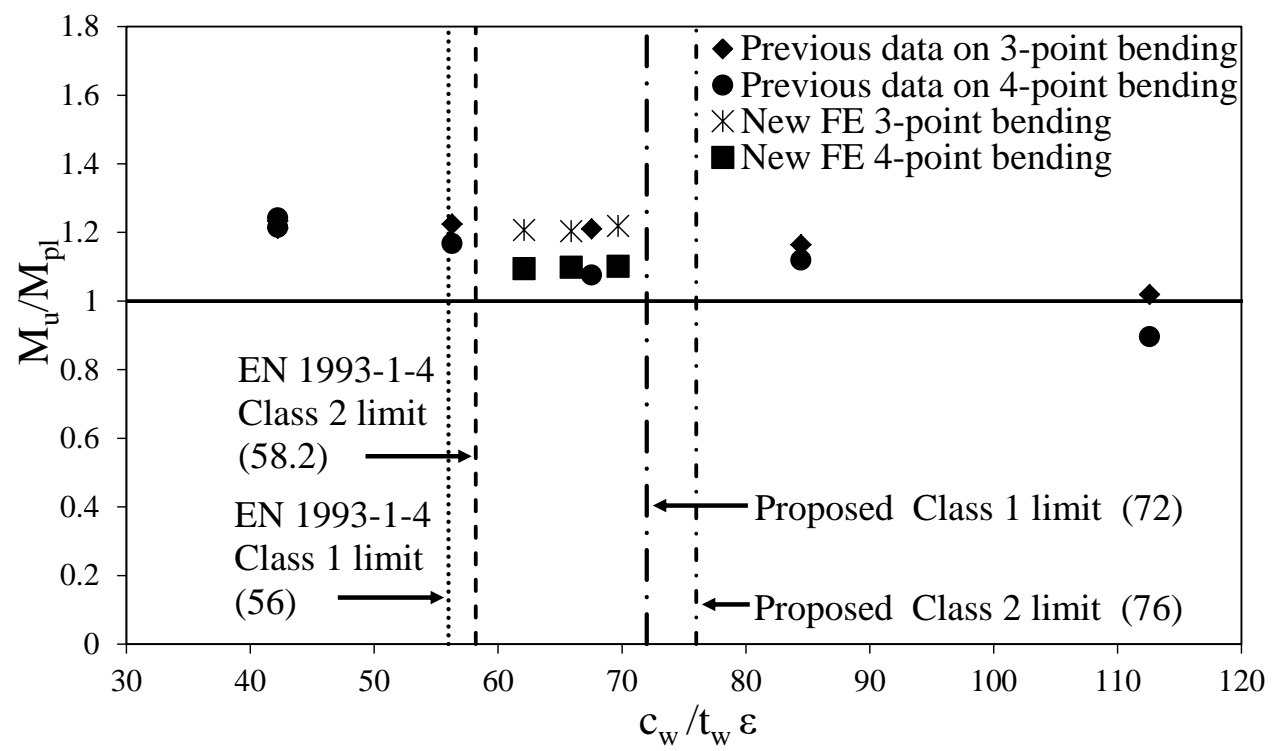

\section{Continuous Strength Method}

The results of this study and previous researches indicate the conservatism of the current codified limits and therefore adopting alternative design approaches such as the CSM is recommended. The bending capacities of each of the tested FE models were calculated according to the CSM and compared to those of EN 1993-1-4 (2006) and the proposed equations of Gardner and Theofanous (2008) presented in Table 4. It is worth noting that by the time of writing the paper of Saliba and Gardner (2013a) a different set of the CSM equations was used - the ones proposed by Gardner et al. (2011) (referred to herein as CSM $_{\text {old }}$ ). In this study, the equations of Gardner et al. (2011) and Afshan and Gardner (2013) (referred to herein as $\mathrm{CSM}_{\text {new }}$ ) were both utilized. It can be seen that the proposed limits (Gardner and Theofanous, 2008) present, on average, a slight improvement over the EN 1993-1-4 (2006) calculated bending capacities (i.e. 4\% on average). Whereas, on average, the CSM offers an enhancement, for stocky cross-sections (i.e. $\bar{\lambda}_{\mathrm{p}} \leq 0.68$ ), of $11 \%$ in comparison to the EN 1993-1-4 (2006) calculated capacities. Hence, its implementation in future revisions of the code is recommended. It is worth noting that no major differences between the $\mathrm{CSM}_{\text {old }}$ and $\mathrm{CSM}_{\text {new }}$ predictions are noticed. The reason behind the proposal of the latest CSM equations (i.e. $\mathrm{CSM}_{\text {new }}$ ) is presented in Afshan and Gardner (2013). 
Table 4. Summary of Bending Capacities of the FE Models Calculated according to EN 1993-1-4 (2006), Proposed Limits (Gardner and Theofanous, 2008) and the CSM (Gardner et al., 2011; Afshan and Gardner, 2013)

\begin{tabular}{|c|c|c|c|c|c|}
\hline Test type & Cross-section & EN1993-1-4/Test & Proposed/Test & $\mathrm{CSM}_{\text {old }} /$ Test & $\operatorname{CSM}_{\text {new }} /$ Test \\
\hline \multirow{12}{*}{3 -point bending tests } & $\mathrm{I}-180 \times 120 \times 6 \times 4-1$ & 0.70 & 0.75 & - & - \\
\hline & $\mathrm{I}-180 \times 120 \times 8 \times 6-1$ & 0.71 & 0.80 & 0.84 & 0.82 \\
\hline & $\mathrm{I}-180 \times 120 \times 10 \times 6-1$ & 0.69 & 0.69 & 0.79 & 0.77 \\
\hline & I- $180 \times 120 \times 15 \times 4-1$ & 0.75 & 0.83 & 0.90 & 0.89 \\
\hline & $\mathrm{I}-190 \times 125 \times 6 \times 4-1$ & 0.75 & 0.75 & - & - \\
\hline & $\mathrm{I}-190 \times 125 \times 8 \times 6-1$ & 0.70 & 0.70 & 0.81 & 0.79 \\
\hline & $\mathrm{I}-190 \times 125 \times 10 \times 6-1$ & 0.71 & 0.71 & 0.79 & 0.78 \\
\hline & I- $190 \times 125 \times 15 \times 4-1$ & 0.75 & 0.83 & 0.89 & 0.87 \\
\hline & $\mathrm{I}-200 \times 130 \times 6 \times 4-1$ & 0.70 & 0.76 & - & - \\
\hline & $\mathrm{I}-200 \times 130 \times 8 \times 6-1$ & 0.70 & 0.70 & 0.80 & 0.78 \\
\hline & $\mathrm{I}-200 \times 130 \times 10 \times 6-1$ & 0.72 & 0.72 & 0.81 & 0.79 \\
\hline & I- $200 \times 130 \times 15 \times 4-1$ & 0.74 & 0.82 & 0.88 & 0.86 \\
\hline \multirow{12}{*}{ 4-point bending tests } & $\mathrm{I}-180 \times 120 \times 6 \times 4-2$ & 0.78 & 0.83 & - & - \\
\hline & $\mathrm{I}-180 \times 120 \times 8 \times 6-2$ & 0.78 & 0.88 & 0.92 & 0.90 \\
\hline & $\mathrm{I}-180 \times 120 \times 10 \times 6-2$ & 0.75 & 0.75 & 0.85 & 0.84 \\
\hline & I- $180 \times 120 \times 15 \times 4-2$ & 0.82 & 0.91 & 1.00 & 0.98 \\
\hline & $\mathrm{I}-190 \times 125 \times 6 \times 4-2$ & 0.74 & 0.81 & - & - \\
\hline & I- $190 \times 125 \times 8 \times 6-2$ & 0.76 & 0.76 & 0.88 & 0.87 \\
\hline & I- $190 \times 125 \times 10 \times 6-2$ & 0.77 & 0.77 & 0.87 & 0.85 \\
\hline & I- $190 \times 125 \times 15 \times 4-2$ & 0.82 & 0.91 & 0.97 & 0.95 \\
\hline & $\mathrm{I}-200 \times 130 \times 6 \times 4-2$ & 0.78 & 0.85 & - & - \\
\hline & $\mathrm{I}-200 \times 130 \times 8 \times 6-2$ & 0.78 & 0.78 & 0.89 & 0.87 \\
\hline & $\mathrm{I}-200 \times 130 \times 10 \times 6-2$ & 0.79 & 0.79 & 0.88 & 0.87 \\
\hline & I- $200 \times 130 \times 15 \times 4-2$ & 0.82 & 0.91 & 0.97 & 0.95 \\
\hline Mean & & 0.75 & 0.79 & 0.88 & 0.86 \\
\hline $\mathrm{COV}$ & & 0.056 & 0.087 & 0.073 & 0.073 \\
\hline
\end{tabular}


Table 5. Summary and Comparisons of Shear Capacities Obtained from the FE Tests, EN 1993-1-4 (2006), EN 1993-1-5 (2006) and Saliba et al. (2014) Predictions

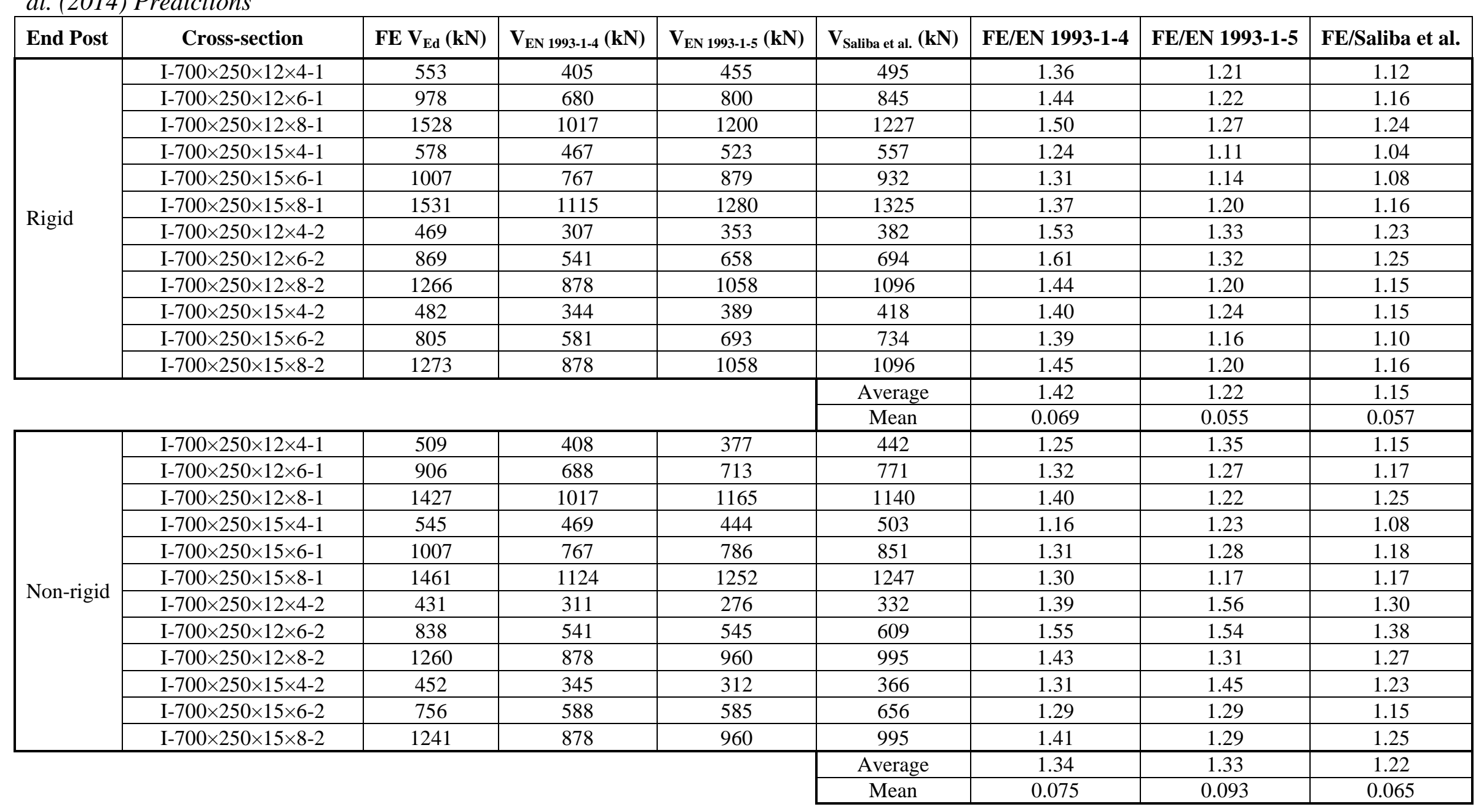


Shear

A total of 24 plate girders with rigid and non-rigid end posts were modelled. The FE models were selected to ensure shear buckling occurs in the webs of the plate girder i.e. a pure shear failure mechanism. A typical example of this failure mode is presented in Figure 3.

Similar to the bending tests, the results obtained from the shear FE tests indicate a similar structural behaviour with existing experimental and numerical data. The results indicate a higher shear capacity for rigid end post sections when compared to the non-rigid ones ( 5\% increase); similar observations were reported by Estrada et al. (2007b). As mentioned earlier, the end post rigidity is not accounted for in the EN 1993-1-4 (2006) equations, and therefore may, in some cases, lead to conservative results. Accordingly, it is recommended to account for the end post rigidity when calculating the ultimate shear resistance of cross-sections.

The comparisons provided in Table 5 show that, on average, the FE results are higher than the EN 1993-1-4 (2006) predictions by $42 \%$ and $34 \%$ for rigid and non-rigid cross-sections, respectively. Furthermore, comparisons show a mean ratio of FE results to EN 1993-1-5 (2006) predictions of 1.22 (coefficient of variation, COV: 0.055) and 1.33 (COV: 0.093), for rigid and non-rigid crosssections, respectively. Major improvements were obtained when adopting the recently proposed equations (Saliba et al., 2014) in which the FE results are now only higher, on average, than Saliba et al. (2014) predictions by $15 \%$ and $22 \%$ for rigid and non-rigid cross-sections, respectively. Furthermore, the equations of Saliba et al. (2014) led to a decrease in the scatter when compared to the codified predictions. The obtained results indicate the conservatism of the codified calculated capacities and highlight the importance of modifying the current stainless steel shear design equations in order to safely exploit the full structural capacity of the cross-sections.

\section{Conclusions}

The aim of this paper is to continue the previous research carried out on lean duplex stainless steel welded I-sections by providing additional structural performance data, derived from finite element modelling, when tested in bending and shear. A background on the existing codified design approaches for both bending and shear and the latest design proposals was provided. A detailed description of the numerical analysis adopted in the current study was presented. A total of forty-eight cross-sections under bending and shear were numerically simulated. The obtained results from the bending finite element tests together with existing experimental and numerical data collected from the relevant literature were used to assess the applicability of the codified slenderness limits and the proposed limits of Gardner and Theofanous (2008) to lean duplex stainless and their accuracy in predicting the bending resistance of stainless steel welded I-sections. It was found that Eurocode 3 for stainless steel limits are conservative 
and better results may be achieved by adopting the proposed limits whereas the greatest improvements were achieved by using the newly developed continuous strength method equations. Similarly, the results obtained from the finite element shear tests indicated that the shear design equations of Eurocode 3 for stainless steel are overly conservative and a distinction between rigid and non-rigid end posts is recommended. Greater improvements in the calculation of shear resistance were achieved through Saliba et al. (2014) proposed shear equations. The adoption of the revised slenderness limits and the recently proposed shear design equations was suggested and the importance of embracing novel design methods such as the continuous strength method was highlighted and recommended. Finally, continuous investigation into the structural behaviour of lean duplex stainless steel is encouraged to help promote its adoption in the construction industry as an economical alternative compared to the commonly used stainless steel grades.

\section{References}

Afshan, S. and Gardner, L. 2013. The continuous strength method for structural stainless steel design. Thin-walled Structures. 68, 42-49.

Anbarasu, M. and Ashraf, M. 2016. Behaviour and design of cold-formed lean duplex stainless steel lipped channel columns. Thin-walled structures. 104, 106-115.

Ashraf, M., Gardner, L. and Nethercot, D. A. (2008). Structural stainless steel design: Resistance based on deformation capacity. Journal of Structural Engineering, ASCE. 134(3), 402-411.

Baddoo, N.R. 2008. Stainless steel in construction: A review of research, application, challenges and opportunities. Journal of Constructional Steel Research. 64, 11, 1199-1206.

Davies, A.W. and Griffith, D.S.C. 1999. Shear strength of steel plate girders. In Proceedings of the Institution of Civil Engineers-Structures and Buildings. 134, 147-157.

EN 10088-4. 2009. Stainless steel - Part 4: Technical delivery conditions for sheet/ plate and strip of corrosion resisting steels for general purposes. CEN.

EN 1993-1-1. 2005. Eurocode 3: Design of steel structures - Part 1.1: General rules General rules and rules for buildings. $C E N$.

EN 1993-1-4. 2006. Eurocode 3: Design of steel structures - Part 1.4: General rules Supplementary rules for stainless steel. CEN.

EN 1993-1-5. 2006. Eurocode 3: Design of steel structures - Part 1.5: Plated Structural elements. $C E N$.

ENV 1993-1-4. 1996. Eurocode 3: Design of steel structures - Part 1.4: General rules - Supplementary rules for stainless steel. CEN.

Estrada, I., Real, E. and Mirambell, E. 2007a. General behaviour and effect of rigid and non-rigid end post in stainless steel plate girders loaded in shear. Part I: Experimental study. Journal of Constructional Steel Research. 63, 7, 970-984.

Estrada, I., Real, E. and Mirambell, E. 2007b. General behaviour and effect of rigid and non-rigid end post in stainless steel plate girders loaded in shear. Part II: Extended numerical study and design proposal. Journal of Constructional Steel Research. 63, 7, 985-996. 
Gardner, L. 2005. The use of stainless steel in structures. Progress in Structural Engineering and Materials. 7, 2, 45-55.

Gardner, L. 2008. The continuous strength method. In Proceedings of the Institution of Civil Engineers-Structures and Buildings. 161, 3, 127-133.

Gardner, L. and Ashraf, M. (2006). Structural design for non-linear metallic materials. Engineering Structures. 28(6), 926-934.

Gardner, L. and Theofanous, M. 2008. Discrete and continuous treatment of local buckling in stainless steel elements. Journal of Constructional Steel Research. 64, $11,1207-1216$.

Gardner, L., Wang, F. and Liew, A. 2011. Influence of strain hardening on the behaviour and design of steel structures. International Journal of Structural Stability and Dynamics. 11, 5, 855-875.

Hassanein, M. 2011. Finite element investigation of shear failure of lean duplex stainless steel plate girders. Thin-walled structures. 49, 8, 964-973.

Hibbitt, Karlsson and Sorensen, Inc. 2012. ABAQUS. ABAQUS/Standard user's manual volumes I-III and ABAQUS CAE manual, Version 6.12, Pawtucket, USA, 2012.

Höglund, T. 1998. Shear buckling resistance of steel and aluminium plate girder. Thinwalled Structures. 29, 1-4, 13-30.

Huang, Y. and Young, B. 2012. Material properties of cold-formed lean duplex stainless steel sections. Thin-walled structures. 54, 72-81.

Huang, Y. and Young, B. 2014. Structural performance of cold-formed lean duplex stainless steel columns. Thin-walled structures. 83, 59-69.

Lecce, M. and Rasmussen, K.J.R. 2006. Distortional buckling of cold-formed stainless steel sections: finite-element modelling and design. Journal of Structural Engineering, ASCE. 132, 4, 505-514.

Patton, M. and Singh, K. 2012. Numerical modelling of lean duplex stainless steel hollow columns of square, $\mathrm{L}^{-}, \mathrm{T}-$, and +- shaped cross sections under pure axial compression. Thin-walled structures. 53, 1-8.

Patton, M. and Singh, K. 2013. Buckling of fix-ended lean duplex stainless steel hollow columns of square, $\mathrm{L}_{-}^{-}, \mathrm{T}-$, and $\mathrm{p}$-shaped sections under pure axial compression -a finite element study. Thin-walled structures. 63, 106-116.

Presta, F., Hendy, C.R. and Turco, E. 2008. Numerical validation of simplified theories for design rules of transversely stiffened plate girders. Structural Engineering. 86, 21, 37-46.

Ramberg, W. and Osgood, W. R. (1943). Description of stress-strain curves by three parameters. Technical Note No 902, National Advisory Committee for Aeronautics Washington, D.C.

Sachidananda, K. and Singh, K. 2015. Numerical study of fixed ended lean duplex stainless steel (LDSS) flat oval hollow stub column under pure axial compression. Thin-walled structures. 96, 105-119.

Saliba, N. 2012. Structural behaviour of lean duplex stainless steel welded I-sections [PhD thesis]. Department of Civil and Environmental Engineering, Imperial College London, UK.

Saliba, N. and Gardner, L. 2013a. Cross-section stability of lean duplex stainless steel welded I-sections. Journal of Constructional Steel Research. 80, 1-14.

Saliba, N. and Gardner, L. 2013b. Experimental study of the shear response of lean duplex stainless steel plate girders. Engineering Structures. 46, 375-391.

Saliba, N., Real, E. and Gardner, L. 2014. Shear design recommendations for stainless steel plate girders. Engineering Structures. 59, 220-228. 
Vol. 5, No. $1 \quad$ Saliba et al.: Numerical Modelling of Lean Duplex Stainless Steel...

Saliba, N. and Gardner, L. 2015. Extension of the continuous strength method to the determination of shear resistance. In Proceedings of the 13th Nordic Steel Construction Conference. 235-236.

Sieurin, H. and Sandström, R. and Westin, E.M. 2007. Fracture toughness of the lean duplex stainless steel LDX 2101. Metallurgical and Material Transactions A. 37, $10,2975-2981$.

Theofanous, M. and Gardner, L. 2009. Testing and numerical modelling of lean duplex stainless steel hollow section columns. Engineering Structures. 31, 12, 3047-3058.

Theofanous, M. and Gardner, L. 2010. Experimental and numerical studies of lean duplex stainless steel beams. Journal of Constructional Steel Research. 66, 6, 816-825. 